\title{
"SE TEM UMA COISA QUE ME DEIXA MUITO FELIZ É PODER ACORDAR DE MANHÃ E SABER QUE O FEMINISMO EXISTE E ELE ESTÁ SENDO DEBATIDO E FALADO": ENTREVISTA COM NATÁLIA BORGES POLESSO $^{1}$
}

\author{
“IF THERE'S ONE THING THAT MAKES ME VERY HAPPY, \\ IT'S BEING ABLE TO WAKE UP IN THE MORNING \\ AND KNOW THAT FEMINISM EXISTS AND IT IS BEING \\ DEBATED AND SPOKEN": INTERVIEW WITH NATÁLIA \\ BORGES POLESSO
}

Jorge Vicente Valentim ${ }^{2}$

1 Escritora e tradutora. Doutora em Teoria da Literatura pela Pontifícia Universidade Católica do Rio Grande do Sul (PUC-RS). Realizou Estágio de Pós-Doutorado (PNPD/CAPES), na Universidade de Caxias do Sul, em 2017. Como ficcionista, publicou Recortes para álbum de fotografia sem gente (2013), ganhador do Prêmio Açorianos; Amora (2015), com o qual ganhou o Prêmio Jabuti 2016, na categoria "Conto". Em 2019, lançou seu primeiro romance, Controle, sob a chancela da Companhia das Letras.

2 Professor Associado de Literaturas de Lìngua Portuguesa do Departamento de Letras e Professor Permanente do Programa de Pós-Graduação em Estudos de Literatura da Universidade Federal de São Carlos (UFSCar). Vice-Presidente da Associação Brasileira de Professores de Literatura Portuguesa (ABRAPLIP)/Gestões 2016-2017 e 2020-2021. 
Resumo: Entrevista com a escritora brasileira Natália Borges Polesso, sobre temas específicos do seu projeto de criação e das suas principais linhas de reflexão. Concedida no momento em que concluía a escrita do seu mais recente romance (Controle, 2020), a conversa constitui uma oportunidade singular para pensar alguns assuntos pontuais da atualidade, sobretudo, o feminismo e como a autora o absorve no seu exercício ficcional.

Palavras-chave: Feminismo, produção literária, ficção brasileira, Natália Borges Polesso. 
Abstract: Interview with the Brazilian writer Natália Borges Polesso, on specific themes of her creative project and of her main lines of reflection. Granted at the time the writing of her most recent novel was completed (Controle, 2020), the conversation constitutes a unique opportunity to think about some punctual subjects of today, especially feminism and how the author absorbs it in her fictional exercise.

Keywords: Feminism, literary production, Brazilian fiction, Natália Borges Polesso. 
Paraty, 27 de julho de 2017. No segundo dia da Festa Literária Internacional de Paraty, tive a oportunidade de conhecer pessoalmente e entrevistar a escritora Natalia Borges Polesso. Os primeiros contatos foram feitos via rede social e, desde então, ela vinha se mostrando receptiva e aberta para a conversa. $\mathrm{Na}$ data escolhida para o encontro, o dono de uma rede nacional de cafeterias disponibilizou o espaço uma hora antes de sua abertura para que tivéssemos um espaço tranquilo para a entrevista. E foi um dos momentos mais incríveis. Estava diante de uma pessoa com uma energia positiva, para além de sua concepção muito bem definida do projeto de criação. Abordando temas como homoafetividades, sexualidades, construção de personagens e narradoras e feminismo, Natalia Borges Polesso foi generosa e pontual nas suas considerações.

Jorge Vicente Valentim - Antes de mais nada, muito obrigado pela disponibilidade de conceder este bate-papo no meio de tantos compromissos já agendados. Como sempre gosto de iniciar a conversa, quando entramos no Google para buscar e, enfim, verificar alguma informação sobre um(a) determinado(a) autor(a), encontramos sempre informações frias (nasceu em tal ano, é natural de tal cidade, escreveu tantos livros, etc). No seu caso, além de escritora e tradutora, é preciso destacar o reconhecimento dos seus pares. Com uma trajetó- 
ria em início, você já tem no seu currículo prêmios importantes, como o Açorianos e o Jabuti. Por isso, minha primeira pergunta, sobretudo para o leitor mais interessado em conhecer a autora, quem é Natália Borges Polesso?

Natália Borges Polesso - (risos) Pergunta para eu deitar no divã, não é não? Bom, eu demorei muito para me aceitar, me entender e me assumir como escritora. Grande parte da minha vida atualmente gira em torno da compreensão e da construção desse ofício. Mas, também, me entender como ser humano, como mulher e como alguém que escreve. Sendo assim, como alguém que escreve, quero falar de coisas importantes na minha vida, a partir de um ponto de vista muito pessoal sobre assuntos que eu considero relevantes e que eu não encontrava com frequência em outros textos. A literatura sempre cruzou a minha vida, desde muito cedo, não apenas como leitora, mas também como contadora mirim de histórias, enfim, como uma criança interessada e curiosa. Natália é bem isso. Além, é claro, de ser uma esposa dedicada (risos). Acabei de casar e estou muito feliz com isso. É engraçada essa situação de você poder levar sua vida pessoal de forma tranquila e desempenhar seu ofício de escrever, falando de coisas que povoam seu cotidiano. Algumas pessoas chegam a me perguntar "Você não vai cansar de falar sobre esses temas?", mas como posso? Seria quase que me perguntar "Por 
acaso eu estou cansada de viver a minha vida?". Não, é obvio. É isso.

JVV - Eu lembro que, em 2016, no Congresso da ABEH (Associação Brasileira de Estudos da Homocultura), Conceição Evaristo fez uma belíssima comunicação sobre o seu livro Amora (2015). Nessa obra, falando um pouco mais sobre suas criaturas, as suas personagens femininas são marcadas por um profundo poder de decisão. Elas são muito decididas. Na minha opinião, a Vó Clarissa (do conto "Vó, a senhora é lésbica?") constitui um exemplo emblemático dessa potencialidade. E você surge na cena literária brasileira, num momento exatamente quando se fala muito de empoderamentos femininos. Você se considera, ou não tem qualquer tipo de restrição que te considerem, uma escritora feminista?

NBP - Absolutamente! Restrição zero. Porque, parafraseando uma amiga minha, Moema Vilela, se tem uma coisa que me deixa muito feliz é poder acordar de manhã e saber que o feminismo existe e ele está sendo debatido e falado. Nossa, é muito cansativo você ter de ouvir certas coisas e achar que elas são aceitas como normais e normalizadas. Ok você ouve absurdos, você ouve o seu trabalho ser questionado por causa de um tema, quando você poderia até ser questionada em outros pontos, sobretudo, os estéticos que o livro tem. 0 temático é 
importante, mas ele não pode ser reduzido a isso. Uma das primeiras resenhas que saiu do Amora foi uma resenha feminista. 0 título era, inclusive, "Amora: uma leitura feminista". ${ }^{3}$ E eu amei isso, porque eu acho que as pessoas têm de pegar o livro e dizer o que elas quiserem sobre ele. Se ele é uma bandeira de empoderamento, por exemplo. Esse foi um aspecto em que eu fui muito confrontada depois da publicação de Amora, porque os meus outros dois livros têm alguma coisa que pende mais para pensar sobre as identidades homoafetivas, mas não tanto como o Amora. Nele, o leitor encontra personagens mais completas, mais redondas, digamos assim. Por causa disso, fui muito confrontada, como te disse, e com perguntas do tipo “Ah, seu livro é um livro político?”. Bom, eu preciso dizer que sim, ele é sim, mas ele não pode ser simplesmente reduzido apenas a isso, entendes? É um livro lésbico, sim, eu tenho que dizer que sim porque essa é uma questão chave, ela é uma questão política também, porque, veja só, você trabalha com o tema e sabe que não se trata de faltar esse tipo de narrativa, mas ela não circula, ela não chega com facilidade nos lugares. A gente mesmo não consegue se encontrar. Eu sei que a temática é importante, mas ele possui coisas mais complexas ali também. Por isso, eu procurei fugir de um recor-

3 Trata-se da resenha de Camila Doval, publicada na Revista virtual Nonada, disponível em http://www.nonada.com. br/2015/10/amora-uma-leitura-feminista/ 
te baseado em faixa etária, em grupo social, onde geralmente encontramos certas personagens, mas eu também preciso dizer que é um livro lésbico do ponto de vista estético porque, em todas as situações de construção das personagens e dos pontos de vista que lá estão, a característica e a identidade lésbicas são fundamentais. Esses dois pontos estão ali como motivadores e causadores de um estranhamento, como um choque, mas também como encantamento. Enfim.

JVV - Geralmente, você se defronta com a pergunta sobre quais autores(as) mais exerceram um tipo de influência sobre sua escrita. Mas, eu vou por outro viés. 0 contista argentino Jorge Luis Borges tem um texto magnífico, intitulado "Kafka e seus precursores", onde procura detectar como certos detalhes temáticos e estéticos do projeto ficcional do autor de $A$ metamorfose podem já surgir em escritores anteriores, formando, assim, uma espécie mesmo de linhagem, mas não marcada pelo passado, mas sustentada e alicerçada no presente. Ou seja, a grande modernidade de Kafka reside na possibilidade de você poder encontrá-lo em autores anteriores a ele. Então, valendo-me dessa imagem, de quem você se considera uma leitora? Quem são aqueles(as) que te seduzem enquanto leitora?

NBP - Entendi. Bom, preciso confessar que essas coisas tem mudado muito para mim nesses quatro úl- 
timos anos, porque nesse período eu decidi me dedicar mais à leitura de literatura contemporânea. E ler mais mulheres e tentar variar um pouco o meu leque de leituras, tanto de outros países, quanto de gêneros. No fundo, eu fui aquela estudante que entrou no curso de Letras e que queria ler Shakespeare, de vez em quando pegava lá também um Nietzsche. Mas, não é isso, apesar de eu gostar muito de Shakespeare. Eu tenho os meus escritores de coração. Julio Cortazar, por exemplo, foi fundamental para eu poder mudar a minha concepção e entender a estrutura do conto. Eu sou muito fã de um livro dele, que é super lado B (risos), que se chama Histórias de cronópios e de famas (1962), onde ele tem aquela prosa mais curtinha e muito sedutora. Depois, a partir dele, acabei por encontrar Marina Colassanti e Lydia Davis. Então, são caminhos labirínticos e meio erráticos, que se ligam por alguma coisa. Hoje, eu posso dizer que sou uma leitora dos meus colegas, de quem está fazendo literatura agora. Por exemplo, precisei mediar uma mesa ano passado com a Veronica Stigger, e eu praticamente devorei tudo dela. Para mim foi ótimo porque eu acho a Veronica uma escritora fantástica! A Angélica Freitas também eu gosto muito, a Marília Garcia tem uma sensibilidade tremenda no escrever, a Paloma Vidal tem uma prosa muito forte, a própria Conceição Evaristo tem um poder narrativo à flor da pele. 
JVV - Inclusive a Paloma Vidal é quem você utiliza como epígrafe do seu livro.

NBP - Exatamente.

JVV - Você tocou, agora, num ponto crucial, porque você escolheu um gênero para escrever que já tem uma presença consolidada na tradição da literatura brasileira. Se olharmos, lá atrás, no século XIX, o nome de Machado de Assis surge imediatamente. Mas, se observarmos o século XX até o momento atual, podemos observar grandes contistas e com a presença muito forte de mulheres. Lembro, por exemplo, a Ligia Fagundes Telles, a Clarice Lispector, a Nélida Piñon, mais recentemente, a Veronica Stigger, a Carol Rodrigues, enfim, você se afirma num gênero que não o romance, por exemplo. Existe alguma razão especial pela escolha do gênero "conto" ou foi uma decisão aleatória? Como se deu esse processo de criação, sobretudo, se observarmos o seu primeiro livro e, agora, o Amora?

NBP - Você mencionou três escritoras que considero fundamentais e que eu li muito: Clarice, Ligia e Nélida. Por essa formação e pelo fato de eu ter escrito alguns contos para jornais, lá em Caxias do Sul mesmo, eu acabei me inscrevendo em concursos locais de contos, porque entendia que a narrativa curta era mais fácil e me permitia esse desafio. Além do que essa coisa de história mais curta sempre me seduziu, então, tudo isso foi meio natural para 
mim, entrar no mundo do conto, embora todos eles sejam muito diferentes uns dos outros, claro. 0 livro de poemas (Coração à corda, 2015) já é mais uma curva, um desvio (risos). Aliás, eu acho que eu preciso aprender e ler muito poesia para poder escrever um outro livro de poema. Quanto ao conto, é um tipo de texto que me seduz e que eu me sinto muito satisfeita em fazer. Também gosto muito de experimentar em cima do conto, porque acredito que seja muito mais fácil tentar coisas diferentes com a narrativa curta. 0 Amora, por exemplo, tem toda uma diversidade de construção do conto, porque, ali, você tem diálogos (seja usando o discurso direto, seja o indireto livre)...

\section{JVV - Você tem a inclusão de e-mails...}

NBP - Sim, tem e-mails, tem contos em modo dramático. Os últimos contos são muito parecidos com os de Recortes para álbum de fotografias sem gente (2013), há outros mais imagéticos, mais poéticos. Enfim, eu fico muito satisfeita poder experimentar toda essa gama de possibilidades nas histórias curtas, por isso que eu escolhi o conto. Agora, estou trabalhando num romance ${ }^{4}$, então, eu sei que é um pouco mais de sofrimento (risos).

JVV - O conto, de uma certa maneira, te fornece uma espécie de controle sobre as estruturas narrativas

4 Trata-se do romance Controle, publicado em 2019, pela Companhia das Letras. 
e que você precisa dominar dentro de uma certa condensação, já que você não pode fugir daquilo, certo? Por outro lado, o romance sugere uma expansão e uma liberdade que, muitas vezes, podem ser traiçoeiras, ou não?

NBP - Sim, eu acredito que sim, mas não posso falar ainda sobre esse romance. Fica uma expectativa (risos).

JVV - Os seus contos tem uma dicção muito singular. Alguns falam de homoerotismo feminino, outros falam (aliás, ouvi isso de uma amiga minha portuguesa e que achei fantástica a expressão!) de um erotismo sáfico e, ainda há pouco, você tocou na dicção lésbica. Como você lida com todo esse repertório conceitual vindo da crítica e como você lida com a recepção crítica de suas obras?

NBP - Olha, eu tendo a usar uma palavra que foge do erótico, porque, geralmente, quando a gente fala para o grande público, as pessoas tendem logo a pensar em sexualidade. Eu prefiro usar o termo homoafetivo, porque as mulheres de Amora encontram-se em relações de afeto mesmo!

\section{JVV - E intensas!}

NBP - Sim, muitas delas, sim! Um dos meus contos favoritos de Amora é "Flor, flores, ferro torcido". Aquilo é uma relação de afeto muito intensa, porque essa menina de oito anos conhece uma vizinha 
que não consegue encaixar em nenhum estereótipo de mulher, por isso ela a associa imediatamente ao gaiteiro, ao Renato Borghetti. Ela se sente extremamente tocada por aquele ser humano que ela não consegue encaixar em lugar nenhum. Ela ouve a mãe chamar a vizinha de "machorra", e, então, ela fica tentando entender o que é isso, o que é uma "machorra"? Por que a vizinha fica triste e, ao mesmo tempo, ela mesma fica pensando, será que ela é doente? A outra vizinha, a Flor, ela também se afeta e, quando aparece, questiona se também não teria a mesma doença da outra, percebe-se que, entre as personagens, existe uma relação, mas não é erótica, é de afeto! Outro conto de que eu gosto muito é "Marília acorda". Esse conto está todo confinado dentro de uma casa. Tudo se passa na casa de umas velhas estranhas, e há um muro barrando a relação delas. Daí são duas relações: uma que se passa dentro da casa e outra que se estabelece com as pessoas do lado de fora dessa casa. Na verdade, são duas personagens que tentam se relacionar já no final da vida, e a relação se torna de afeto, no sentido de que como uma vai lidar com o mundo, depois da perda, se há um muro que impede o contato direto com as outras pessoas? Como eu vou sentir a minha dor e como eu vou me emocionar? Então, eu tento buscar algo mais. Claro que, no livro, há contos mais eróticos, inclusive sobre a própria descoberta, como é o caso do primeiro conto ("Primeiras 
vezes"). É uma tomada de decisão! É uma menina que tem a sua primeira vez com uma menina e, depois, com um menino. No final, fica implícito que ela segue pelo caminho homo.

JVV - Como já falamos aqui, as suas personagens são marcadas por uma intensidade visível. Mas há algumas delas que me tocam particularmente. Uma delas é a Eduarda, de "Não desmaia, Eduarda", que chega ao ponto de tomar um porre e desencadear uma série de reflexões importantes.

NBP - Adoro a Eduarda. Aliás, não sei se gosto mais da Eduarda ou da mãe dela (risos).

JVV - E, também, a Joana e a Vó Clarissa (de “Vó, a senhora é lésbica?"). A relação dessas duas personagens é absolutamente fantástica. São situações muito próximas do cotidiano, mas que não chegam perto daquilo que a crítica convencionou chamar de "hiper-realismo", mas são de um realismo cotidiano muito direto e que acaba por esbarrar na questão da homoafetividade. Em que medida essa aproximação com o imediato cotidiano não pode ser pensada como um espelhamento autobiográfi$\mathrm{co}$ ?

NBP - Hummm (risos). Não fugir da resposta (risos). Eu acho que é impossível que o escritor não dê algo às suas personagens. Você não precisa dar a sua biografia para elas, mas o modo de olhar o mundo, 
algum recorte ou alguma coisa que chamou a atenção, inevitavelmente, você acaba dando isso para elas. E como Amora tem essas personagens lésbicas, tem muita coisa da minha vida que perpassa esses contos, mas não necessariamente as minhas vivências. Por exemplo, em "Não desmaia, Eduarda", tem um pedacinho de uma história fantástica que ouvi de uma amiga minha. Eu transformei a mãe dela naquela mulher histérica, que grita, não é? (risos) Depois, essa minha amiga me contou que deu o conto para a mãe dela ler e ela se identificou com a personagem, mas eu avisei que nem conhecia a mãe dela (risos). "Tia Marga” tem um outro pedacinho de outra história de uma amiga, que tinha uma tia assim, assado. Daí, eu acabei misturando um pouco e o resultado está lá.

JVV - Um outro aspecto muito particular nos seus contos encontra-se na construção dos seus narradores, ou melhor, de suas narradoras: há uma quantidade expressiva de vozes na $1^{\underline{a}}$ pessoa. Conforme você bem esclareceu há pouco, é claro que você não vai colocar ali a sua biografia completa e de forma diacrônica, mas fica visível uma aproximação com as suas vivências, a partir da escolha da voz que vai contar a história dos seus textos, ou estou enganado?

NBP - Nossa, você leu mesmo (risos). Bem, essa questão dos narradores foi uma questão muito forte 
para mim. Alguns contos eu escrevi com um ponto de vista, e depois mudei completamente na versão final, simplesmente, porque ele não me convenceu daquele jeito. E agora, eu realmente não lembro exatamente da quantidade (risos).

JVV - São muitos, com certeza (risos). Dos 33 contos, 25 são em $1^{a}$ pessoa e 8 em $3^{\underline{a}}$ pessoa.

NBP - Obrigada, porque eu mesma não tinha ideia (risos). Na verdade, alguns foram um verdadeiro desafio para a construção do narrador. Um deles, com certeza, foi "Vó, a senhora é lésbica?".

\section{JVV - Por que?}

NBP - Porque são duas histórias dentro de um conto só. Apesar do foco, ali, recair sobre a Joana, o ponto chave é a saída do armário, o coming out da avó, uma senhora de idade! Falar de homoafetividade e velhice parece, ainda, um tabu nos dias atuais. $\mathrm{Na}$ verdade, o que eu tentei fazer ao longo de Amora foi experimentar em qual voz tal história ganharia credibilidade. E isso é uma coisa que eu estou sofrendo imensamente no meu romance, porque eu tenho 3 versões dele: uma em $1^{\text {a }}$ pessoa, uma em $3^{\text {a }}$ pessoa e outra com múltiplos narradores. Eu já estou na página 48 e eu preciso me decidir (risos). Realmente há coisas em que as personagens precisam estar contando a sua história. Em Amora, eu percebi que não faria sentido o uso da $3^{\underline{a}}$ pessoa 
em alguns casos, mas, por outro lado, é preciso fazer um malabarismo para poder contar em $1^{\mathrm{a}}$ pessoa, até para poder conseguir fazer flash backs e progressões, e que funcionem para a história ficar fechada. Enfim, a escolha das minhas narradoras foi esse processo, de tentar pensar esteticamente como a história precisava ser contada, o que vai ficar melhor, o que vai ficar mais convincente, e dar voz mesmo a essas mulheres.

JVV - Encaminhando para a conclusão, não poderia terminar sem falar exatamente no conto que dá o título ao seu livro, "Amora". Logo na entrada, você dedica "Aos amores e às amoras". Depois, no conto propriamente dito, a sua protagonista Amora é uma exímia jogadora de xadrez. Ela domina o tabuleiro de forma absoluta e só perde a medalha de outro porque se confronta com uma desafiante e não com um menino. Por fim, também não posso deixar de observar que Amora é a soma de Amor + a, ou seja, o seu livro tem a necessidade de registrar histórias de amor no feminino. No entanto, em que medida, a sua protagonista e o conto "Amora" não podem representar, muito metatextualmente, o seu domínio da narrativa (como um jogo de xadrez)? Quem você espera se sentar diante do seu texto? O leitor ameno e descompromissado ou o leitor crítico, com uma postura de desafio como quem não se contenta com a medalha de prata e 
quer a medalha de ouro? (risos) Afinal, você é leitora de Julio Cortázar, não? (risos)

NBP - Adorei essa sua leitura! (risos) Confesso que você está me dando uma metáfora e que eu nunca pensei nela (risos). Falando sério, fico muito satisfeita e confortável em saber que Amora te despertou todas essas inquietações e que não dizem respeito só sobre as homoafetividades. Não estou dizendo que elas não são importantes, é claro que são, se não, não teria escrito os contos. Mas, o fato é que o labirinto, o movimento, a reflexão são componentes importantes para um autor. No meu caso, saber que os contos te levaram a todas essas perguntas sobre as homoafetividades e também sobre o meu processo de criação, isso me dá uma grande alegria. Na verdade, sim, o título original seria Amor $A$, mas como eu não sabia como seria a reação das pessoas diante do livro, decidi deixar Amora, com um conto homônimo no seu conjunto. Ele foi um dos últimos a serem escritos e dei o nome da personagem o mesmo do livro. Vou te dizer que, de todos os contos, esse é o mais autobiográfico, tudo ali existiu na minha vida, eu jogava xadrez, existiu a Angélica, não existiu o romance, como o da Amora e da Angélica, mas tudo ali é muito autobiográfico: a bicicleta, os amigos, o cara me confundindo com menino (risos). E, veja bem, no "Amora”, nada de muito grave acontece. É uma menina que está tendo a sua primeira paixão com um rapaz, que a con- 
funde ("Você não tem uma irmã que joga xadrez?"), e só depois da transformação na adolescência, quando ela poderia tocar e atingir outros meninos, ela se apaixona por uma outra menina. Para mim, esse conto é muito querido, porque - ele não resume - ele integra o amor no feminino. Afinal, a primeira vez em que ela vai sentir alguma coisa mais profunda será exatamente com essa menina, com a Angélica. Na verdade, ela não tinha nome, mas, ao terminar de ler, eu me dei conta de que ela precisava se chamar Amora. E assim nasceu. Quanto à metáfora do jogo, isso eu não posso comentar porque você acabou de me oferecer de presente (risos).

\section{JVV - Quais são seus planos futuros?}

NBP - Bom, você é professor, então, você conhece bem a rotina. Acabei de passar num Pós-Doc, logo, meus planos futuros estão bem ligados à vida acadêmica. Além da questão da escrita, eu gosto muito de dar aula e adoro ler teoria. Eu passei com um projeto que se chama "Geografias lésbicas", por isso, a minha preocupação no mapeamento e no contato com obras que possibilitem essas leituras. Ainda estou em processo de finalização do romance e, em breve, ele deve ser publicado.

JVV - Muito obrigado pelo seu tempo e pela sua atenção. E muito sucesso!

NBP - Eu é que agradeço a tua atenção e leitura. 